\title{
New activation methods used in green chemistry for the synthesis of high added value molecules
}

\author{
Maité Sylla-Iyarreta Veitía $\cdot$ Clotilde Ferroud
}

Received: 30 June 2014/ Accepted: 21 October 2014/Published online: 22 November 2014

(C) The Author(s) 2014. This article is published with open access at Springerlink.com

\begin{abstract}
In the chemical and pharmaceutical industry, molecular organic chemistry is undergoing a green revolution in order to avoid waste by developing a cleaner and safer chemistry. This change is subject to the new European regulation REACH. One of the major goals of organic synthesis is to design molecules with high added value by developing synthetic methods highly selective, economical and environmentally friendly. To satisfy the societal expectation new activation methods must be developed in order to shorten the synthesis, to respect the principle of atom economy and to substitute pollutants or toxic organic solvents. In this context, our group focuses its research on the synthesis of biologically active molecules, developing new environmentally friendly synthetic strategies and more energy-efficient alternatives such as microwaves, ultrasound, photochemistry or biotransformation. We present here how various activation methods used for the preparation of several high-value compounds can dramatically enhance yields and selectivity. First, we describe microwave-assisted syntheses of precursors of $\left[{ }^{11} \mathrm{C}\right] \mathrm{PIB}$, a tracer used in PET imaging and amides intermediates of natural products. We describe also the selective reduction of nitro compounds using ultrasound activation and a facile pathway to obtain $\beta^{3}$-chiral aminoacids by biotransformation using purified nitrilases. Finally the results concerning the alkylation of $\alpha$-aldehydes, using visible light and dyes as catalysts without transition metal are discussed. Some general considerations concerning the
\end{abstract}

Published in the Special Issue "Energy, Environment, Economics and Thermodynamics".

M. S.-I. Veitía $(\bowtie) \cdot$ C. Ferroud

Laboratoire Chimie moléculaire génie des procédés chimiques et énergétiques (CMGPCE), EA 7341, Conservatoire national des arts et métiers, 2 rue Conté, 75003 Paris, France

e-mail: maite.sylla@cnam.fr activation methods and their impact on the environment and the energy saving are given.

Keywords Green chemistry · Environment · Energy economy · Biotransformation - Microwaves activation . Ultrasound · Photocatalysis

\section{Introduction}

In the emerging context in order to build a sustainable society in which mankind will satisfy its needs without compromising the future generations, the "green" chemistry plays a major role in the implementation of innovative, clean and efficient strategies. This "green" chemistry employs the raw materials from biomass and renewable energy producing the minimal wastes [1].

In 2015, $30 \%$ of chemistry will be "green", namely concerning the production of highly specialized materials and bioactive compounds more structurally complex than the compounds prepared by traditional methods. These high added value molecules with a short life span, a high profit margin and made especially for the consumers require the development of new synthetic approaches. To answer the challenges of the industry, the French chemical companies have to innovate and improve their competitiveness, which is based on the development of technical skills on R\&D, engineering, processes, and services [1].

One of the principal factors of mutation inducing the upheavals and changes in the economic models of chemical industry is the improvement of the intrinsic sustainability of chemistry. That is one of concerns for the chemistry science for a sustainable development looking to limit its environmental footprint. The chemical industry can 
contribute significantly to this goal through the following aspects:

- Process The search of sustainability involves necessarily the improvement or optimization of existing processes. Thus, the process intensification increases the process efficiency by reducing equipment size. It has significant benefits in terms of environment. The physicochemical activation such as ultrasound, microwaves, mechanochemistry aims also to reduce energy costs.

- Catalysis It also contributes to process improvement, beyond the expected progress in heterogeneous catalysis using precious metals; the use of white biotechnologies for the manufacture, processing or degradation of molecules presents a significant potential to improve reaction yields.

- Restorative chemistry The fight against pollution through the implementation of techniques reducing air pollution emissions, to process wastes, wastewater and soil. Biotechnology and photocatalysis are interesting methods used to reduce gas emissions and show the importance of a multidisciplinary approach.

\section{Energy, environment and molecular chemistry}

Actually, the technologies developed in chemical and pharmaceutical industries concern simultaneously chemical product design and manufacturing. These processes rapidly change in a context of innovation, and must be synchronized in order both to meet today's economic demands and to remain competitive in global trade taking into account the social and environmental constraints of industrial production processes. Answering this optimization requires a scientific approach of chemical engineering defined as the triplet "molecular processes-product-process engineering" [2]. The ultimate goal is to produce chemicals which require less energy and to become more environmentally responsive.

Chemistry and process engineering should develop systematic procedures for the understanding, design and optimization of all the complex processes that occur at different scales in the chain of chemical production, ranging from nano and micro scales to industrial scale. In this context, green chemistry plays a major role in the implementation of innovative clean, efficient and effective strategies from raw materials and renewable energy while producing minimal waste [2].

The development of sustainable chemistry called "environmentally compatible chemistry" is a major challenge for synthetic chemists. One of the goals of green chemistry is the design of chemical products and processes that reduces or eliminates the use and synthesis of hazardous and toxic substances. To achieve this goal, the synthetic chemist must take into account a number of basic principles (12 principles of green chemistry), as well as, the use of safer solvents and design of chemical products to minimize their toxicity, reduction of by-products, use of catalytic processes, less hazardous chemical syntheses, design energy requirements relative to environmental and economic impacts. This approach should include the whole process, i.e., the reaction and its treatment by limiting the problems of separation and purification [3].

Chemistry and process engineering are faced with new challenges that involve complex systems, from the molecular scale to products and processes. The current methods and the new processes will be gradually adapted to the principles of green chemistry.

One objective of our research unit "Molecular chemistry, chemical and energetic process engineering, CMGPCE" at Conservatoire National des Arts et Métiers, created in January 2014, is the optimization of innovative processes to improve energy efficiency and product quality with high environmental performance, generating clean energy and reducing pollution. The molecular chemistry team is particularly interested in the application of green chemistry principles at molecular level in order to prepare compounds of high added value.

\section{New activation methods used in green chemistry for the synthesis of high added value molecules}

Several physicochemical activation techniques such as microwaves, ultrasound, biotransformation or photocatalysis are part of the green methodologies used for the synthesis of high added value molecules. These methods are used depending on the type of reaction that the organic chemist would like to optimize. We discuss briefly the importance of some activation methods used in our group.

Microwave-assisted heating under controlled conditions has been shown to be an invaluable technology in many areas, from the organic synthesis on solid phase supported to the preparation of functional nanomaterials. The heating is due to the agitation of water molecules contained in the compound. Under the influence of the microwave, the water molecules will begin to change direction at the same frequency of $2.45 \times 10^{9}$ times per second corresponding to a frequency of $2.45 \mathrm{GHz}$. Setting in motion of the water molecules will generate heat. The microwave-assisted synthesis is used in the pharmaceutical, agrochemical and related industries in the initial discovery and in development processes. Its principal interest concerns the dramatic reduction of reaction times and amount of solvent, the increase in product yields, the saving energy for heating by 
focusing efficient energy on the sample and enhancing product purities avoiding possible side reactions. Moreover, the selectivity of certain manufacturing processes could be positively influenced by this technology [4]. Many reaction parameters can be evaluated in a few hours to optimize the desired chemistry. In addition, microwave synthesis allows the discovery of novel reaction pathways, which serve to expand "the chemical and the biological space". The scale-up of microwave synthesis from the laboratory to process and production scale is a challenging area. Two different approaches for microwave synthesis on a larger scale have emerged: batch synthesis in larger multimode reactors or continuous/stop flow techniques [5].

Sonochemistry is the application of ultrasound to chemical reactions and processes. The mechanism causing sonochemical effects in liquids is the phenomenon of acoustic cavitation. Ultrasonic devices use less energy than traditional heating systems and achieve superior processing results and are used in a wide range of sonochemical processes. Cavitation is the formation, growth, and implosive collapse of bubbles in a liquid. Cavitational collapse produces intense local heating $(\sim 5000 \mathrm{~K})$ and high pressures $(\sim 1000 \mathrm{~atm})$. Ultrasonication is an alternative mechanism to heat, pressure, light or electricity to initiate chemical reactions. This technology is nowadays widely used in fine chemistry and environmental chemistry. Among the industrial areas that use it in a conventional way, cleaning is the most outstanding example. In organic synthesis the use of ultrasounds for the activation of radical reactions or one-electron transfer reactions is described in the literature. Thus, ultrasounds allow activation energy, reduced reaction times, improved yields and avoid the addition of phase transfer agents [6].

The increasing importance of chiral compounds in fine chemical and life science sectors gave birth to chirotechnologies. Biotransformation is a preferred method for the control of the selectivity and is widely used in green chemistry. This methodology contributes to the development of chiral chemistry in aqueous medium reconciling the constraints imposed by the efficient synthesis with the constraints related to the respect for the environment.

Since the 1980s, the enormous potential of natural catalysts particularly the enzymes in the transformation of non-natural organic compounds has been widely recognized. These catalysts may be used in the form of whole cells, cellular organelles or as isolated enzymes. The use of enzymes in biotransformation processes has several advantages. They are very efficient, friendly environmentally biocatalysts and they are active under mild conditions (pH 5-8 at $20-40{ }^{\circ} \mathrm{C}$ ) minimizing side reactions. The use of enzymes avoids common problems encountered in conventional methods such as decomposition, isomerization, racemization or rearrangements. Finally, enzymes tolerate a variety of substrates, avoid the use of organic solvents and are chemo-, regio- and stereospecific [7].

The activation by photocatalysis under visible light is another method use in fine chemistry. In the last years, asymmetric organocatalysis has been extensively studied as a complementary technique of organometallic catalysis. This new approach is very attractive because it circumvents the use of heavy metals. Light can be considered as an ideal reagent for environmentally friendly, green chemical synthesis. Unlike many conventional reagents, light is abundant, non-toxic and generates no waste. Nowadays, the development of photoredox catalysis initiated by visible light is of real importance. The one-electron reactions are often performed using, as photoredox catalysts, organometallic complexes containing ruthenium or iridium. However, the potential toxicity of the ruthenium or the iridium salts as well as their future limited availability is the major weakness of these metal-based methods for the manufacturing of fine chemicals and pharmaceuticals. For example, the combination of a photocatalytic process and organocatalysis, is an excellent method to develop enantioselective reactions [8].

In this paper we discuss the results obtained in some studies developed in our group using efficient physicochemical activation methods. The use of microwaves activation is described through the amidation reaction applied to macrocycles synthesis and in a Suzuki-Miyaura coupling applied to the preparation of a series of potential precursors of $\left[{ }^{11} \mathrm{C}\right]$ PIB. We describe also a selective reduction of nitro compounds catalyzed by zinc under ultrasound activation. Finally, the results obtained in the preparation of pure $\beta$-amino acids using nitrilases and the alkylation of $\alpha$-aldehydes, using visible light and dyes as catalysts are discussed.

\section{Methods}

Materials and equipment

The reagents and solvents were purchased from commercial sources and used as received. The monitoring of the reactions was performed by analytical thin layer chromatography (TLC) or by gas chromatography-mass spectrometry (GC-MS). TLC was performed on aluminium sheets precoated with silica gel plates $\left(60 \mathrm{~F}_{254}\right.$, Merck). TLC plates were visualized using the appropriate developer. The enzymes NIT-101-NIT-112 were purchased from the commercial supplier Codexis Biocatalytics, Inc. NIT-107 nitrilase broad-range acidovorax $\mathrm{sp}$. is produced by DuPont.

The reactions using microwaves were accomplished using a single mode microwave reactor (CEM Discover 
$1^{\mathrm{TM}}$ ) monitored by ChemDriver, equipped with a $300 \mathrm{~W}$ power source and onboard infrared temperature sensor. The reactions using ultrasonic activation were accomplished using a Transonic Elma ultrasonic bath, $35 \mathrm{kHz}$. The reactions using activation by photocatalysis were performed using a high-pressure mercury vapour lamp of $150 \mathrm{~W}$ or a fluorescent lamp of $24 \mathrm{~W}$ at $6500 \mathrm{~K}$ or under irradiation LED.

\section{Physical measurements}

The structure of all products prepared by different methods was checked by comparison of their nuclear magnetic resonance (NMR), infrared spectroscopy (IR) and mass spectroscopy (MS) data and by the TLC behaviour. ${ }^{1} \mathrm{H}$ and ${ }^{13} \mathrm{C}$-NMR spectra were acquired on a Bruker BioSpin $\mathrm{GmbH}$ spectrometer $400 \mathrm{MHz}$, at room temperature. Various 2D techniques and DEPT experiments were used when necessary to establish the structures and to assign the signals. Infrared spectra were recorded over the $400-4000 \mathrm{~cm}^{-1}$ range with an Agilent Technologies Cary $630 \mathrm{FTIR} / \mathrm{ATR} / \mathrm{ZnSe}$ spectrometer or with $\mathrm{KBr}$ discs with a Nicolet FT-IR Avatar 320 spectrometer. GC-MS analyses were performed with an Agilent $6890 \mathrm{~N}$ Gas Chromatograph equipped with a dimethyl polysiloxane capillary column. The mass spectra resulting from ionization by electronic impact (EI-LRMS) were acquired on a 5973 Network MSD (Agilent). According to study the highperformance liquid chromatography (HPLC) analyses were carried out on a normal phase column or reverse phase column using a Water 2998 photodiode array detector $(260-370 \mathrm{~nm})$ and an isocratic system of elution or on a chiral phase column.

\section{Amidation reaction procedure}

The amidation of primary amines was carried out in a capped $10 \mathrm{~mL}$ microwave reactor vial. The carboxylic acid derivative $(2.4 \mathrm{mmol})$ and the corresponding amine ( $2 \mathrm{mmol}$ ) were mixed. The tube was positioned in the irradiation cavity and the mixture was heated and stirring under microwave irradiation to $90{ }^{\circ} \mathrm{C}$ with $2 \mathrm{~W}$ of power for about $1 \mathrm{~h}$. After completion, upon cooling to ambient temperature, the conversion was directly determined by GC-MS analyses. A consecutive workup was simply performed by dissolving the reaction mixture in dichloromethane and then concentrated under vacuum.

Suzuki-Miyaura reaction procedure

The Suzuki-Miyaura coupling of the corresponding 2-bromobenzothiazoles $(0.66 \mathrm{mmol})$ and the corresponding phenylboronic acid pinacol ester $(0.79 \mathrm{mmol})$ was performed in anhydrous DMF in the presence of $\mathrm{K}_{2} \mathrm{CO}_{3}$ (6.0 equiv). After $1 \mathrm{~h}$ under argon bubbling, $\mathrm{Pd}(\mathrm{dppf}) \mathrm{Cl}_{2}$ $\mathrm{CH}_{2} \mathrm{Cl}_{2}(0.033 \mathrm{mmol})$ was introduced and the mixture was stirred under microwave irradiation (monitoring by TLC or by GC-MS). After the reaction completed the mixture was filtered on Celite ${ }^{\circledR}$, concentrated and dissolved in $4 \mathrm{~mL}$ of $1 \mathrm{~N} \mathrm{MeOH}-\mathrm{HCl}$. Then $75 \mathrm{~mL}$ of $\mathrm{Et}_{2} \mathrm{O}$ was introduced and a colour powder was isolated by filtration. The precipitate was poured into water and $\mathrm{pH}$ adjusted to 6 . The expected compounds were isolated by filtration and purity was checked by HPLC.

\section{Reduction of nitrobenzenes procedure}

To a suspension of the corresponding nitro compound ( $3 \mathrm{mmol}$ ) in acetone and saturated $\mathrm{NH}_{4} \mathrm{Cl}$ aqueous solution was added distilled water until the solution became clear. Zinc dust (2.1 equiv) was added slowly by portions while sonicating the reaction mixture at $15-20{ }^{\circ} \mathrm{C}$ for $5-10 \mathrm{~min}$. The crude mixture was concentrated under reduced pressure and a temperature never exceeding $15^{\circ} \mathrm{C}$. The residue obtained was dissolved in $\mathrm{CH}_{2} \mathrm{Cl}_{2}$ at $0{ }^{\circ} \mathrm{C}$. The organic phase was dried over magnesium sulfate, and then concentrated as above to provide the desired hydroxylamine.

\section{Biotransformation screening procedure}

For biotransformation experiments, the corresponding amino nitriles $(0.1 \mathrm{mmol})$ were dissolved in phosphate buffer $(125 \mu \mathrm{L}, 50 \mathrm{mM}$ potassium phosphate, $2 \mathrm{mM}$ DTT, 1 mM EDTA, pH 7.5) and in case of low solubility of the substrate, $\mathrm{MeOH}$ or DMSO was used as cosolvent. The enzyme $(0.5 \mathrm{mg})$ was dissolved in a phosphate buffer $(125 \mu \mathrm{L})$ and was added to the substrate to afford a final concentration of $0.2 \mathrm{M}$. The reaction was stirred with a magnetic bar and the temperature was adjusted to $30^{\circ} \mathrm{C}$. After $18 \mathrm{~h}$, acetone $(500 \mu \mathrm{L})$ was added. The reaction vessels were centrifuged for $15 \mathrm{~min}$ at room temperature at $4,000 \mathrm{rpm}$ to remove precipitated proteins. The $300 \mu \mathrm{L}$ of supernatant was concentrated and then analyzed by RP-18 HPLC using acetonitrile/water/formic acid (60:40:0.1) using an isocratic mode. For the preparative scale, approximately $100 \mathrm{mg}$ of substrate was dissolved in phosphate buffer $(50 \mathrm{mM}$ potassium phosphate, $2 \mathrm{mM}$ DTT, $1 \mathrm{mM}$ EDTA, pH 7.5) in a round-bottomed flask. The commercial enzyme preparation was added as a solution in phosphate buffer to substrate to afford a final concentration of $0.2 \mathrm{M}$. The reaction was stirred with a magnetic bar and the temperature was adjusted to $30-32{ }^{\circ} \mathrm{C}$ by use of an oil bath. The conversion was monitored by HPLC. After completion, the mixture was acidified by addition of $\mathrm{HCl}$ and the protein was removed by $\left(\mathrm{NH}_{4}\right)_{2} \mathrm{SO}_{4}$ precipitation and filtration through a plug of 
Celite ${ }^{\circledR}$. The products were purified by silica gel chromatography $\left(\mathrm{CH}_{2} \mathrm{Cl}_{2} / \mathrm{CH}_{3} \mathrm{OH}\right.$ 95:5).

Enantioselective $\alpha$-alkylation procedure

The enantioselective alkylation of aldehydes was performed in an overnight oven dried Pyrex glass vial equipped with a septum and a dried magnetic stir bar. Rose Bengal $(2.5 \mathrm{mg})$, the catalyst $(24.0 \mathrm{mg}), \mathrm{LiCl}(2.1 \mathrm{mg})$ and diethyl bromomalonate $(84 \mu \mathrm{L})$ were added successively. After purging the container with argon for $1 \mathrm{~min}$, anhydrous DMSO $(0.5 \mathrm{M}, 1 \mathrm{~mL})$ was added followed by hydrocinnamaldehyde $132 \mu \mathrm{L})$ and 2,6-lutidine $(115 \mu \mathrm{L})$. Then the stirred solution was degassed for 10 min under argon bubbling. The mixture was placed $2 \mathrm{~cm}$ from the $24 \mathrm{~W} 6500 \mathrm{~K} 1425 \mathrm{~lm}$ fluorescent light source for irradiation until the complete conversion of the bromide in $2 \mathrm{~h}$ (monitored by TLC and/or GC/MS analysis). Then $10 \mathrm{~mL}$ of water was added and the resulting solution was extracted with ethyl acetate $(3 \times 10 \mathrm{~mL})$. The combined organic layers were dried over anhydrous $\mathrm{MgSO}_{4}$ and concentrated in vacuo. The crude product was purified by silica gel chromatography using cyclohexane: ethyl acetate (95:5) to afford the desired alkylation product.

\section{Results and discussion}

Microwaves assisted solvent—free amidation

While important efforts were made in the development of positron emission tomography (PET) tracers for the in vivo molecular diagnosis of Alzheimer's disease, very few investigations to develop magnetic resonance imaging (MRI) probes were performed. We have developed a new generation of $\mathrm{Gd}(\mathrm{III})$-based contrast agents to detect the amyloid $\beta$-protein aggregates by MRI, one of the earliest biological hallmarks of the pathology. These compounds are azapyridinomacrocycles complexing metal cations such as $\mathrm{Gd}(\mathrm{III})$. They must cross the biological barriers and vectorize the therapeutic target [9].

In order to synthesize these lipophilic azapyridinomacrocycles we had to prepare a linker via an amidation reaction. The satisfactory results obtained under microwaves activation led us to develop a method to control the chemo- and regioselectivity in the amidation of polyamines. Previous studies have shown that microwave assisted amidation reactions result in a specific nonthermal microwave effect. This effect can be explained by an increase of the polarity of the dipolar transition state. The applications implement high power which leads to high temperatures, often incompatible with the control on selectivity in polyfunctional molecules. Thanks to the

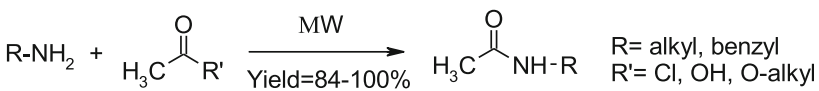

$$
\begin{aligned}
& 12 \\
& 3
\end{aligned}
$$

Scheme 1 Microwave-assisted amidation of primary amine under mild conditions

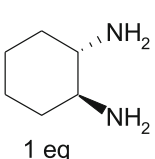

4

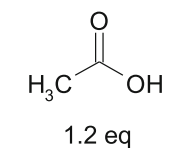

5

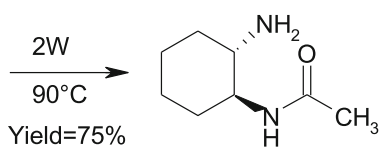

6
Scheme 2 Microwave-assisted amidation of trans cyclohexanediamine 4

specific effect of microwaves, we have achieved the amidation reactions without solvent, in a few minutes at 2-25 W with excellent yields (85-100 \%) [10].

In order to screen the uncatalysed amidation under microwave-assisted solvent-free conditions of primary amines 1, we performed the reaction with various esters as acyl donors 2 in a CEM Discover ${ }^{\mathrm{TM}}$ microwave synthesizer. Neat compounds were mixed in a sealed microwave reaction tube and irradiated under $25 \mathrm{~W}$ or $100 \mathrm{~W}$ for few seconds to few minutes. The reactions were monitored by GC-MS analysis and the purity of the desired products was evaluated by NMR spectroscopy. The desired compounds 3 were afforded with yields of 84-100\% (Scheme 1).

We also investigated the use of acetic acid $\mathbf{5}$, as acylating agent. In that case the control of temperature allowed us to work with heat-sensitive amines and permitted the formation of water as by-product. Whatever the power used (2-25 W), amidation reaction of the primary aliphatic amines took place at $80-90{ }^{\circ} \mathrm{C}$ and was quantitative in 5-15 min. Thus, the conditions (i.e., $2 \mathrm{~W}, 90{ }^{\circ} \mathrm{C}$ ) applied to the amidation of the trans cyclohexanediamine $\mathbf{4}$ led to the formation of the expected monoacetylated product $\mathbf{6}$, with a yield of $75 \%$ (Scheme 2) [10].

We were also interested in the $N$-acetylation of secondary amines and the study of selectivity of primary versus secondary amines. The conditions discussed above (i.e., 2, $90 \mathrm{~W}, 10$ or $130{ }^{\circ} \mathrm{C}$ ) were applied to the acetamidation of $\mathrm{N}$ 3-(aminopropyl) cyclohexylamine 7, $N$-propylethane-1, 2-diamine 8 and dibutylamine 9 by the acetic acid (Table 1).

Suzuki-Miyaura cross-coupling assisted by microwaves

The research for a treatment or the early diagnosis of Alzheimer's disease is the current priority. This disease is a progressive neurodegenerative disorder responsible for $60-70 \%$ of dementia cases. About $6 \%$ of the population 
Table 1 Microwave-assisted acetylation of secondary amines and study of selectivity of primary vs secondary

${ }^{a} 10 \mathrm{~W}, 130{ }^{\circ} \mathrm{C}, 2 \mathrm{~h}$

\begin{tabular}{|c|c|c|c|c|}
\hline \multirow[t]{2}{*}{ Amine $(2 \mathrm{mmol})$} & \multicolumn{2}{|c|}{$2 \mathrm{~W}, 90^{\circ} \mathrm{C}, 1 \mathrm{~h}$} & \multicolumn{2}{|c|}{$10 \mathrm{~W}, 130^{\circ} \mathrm{C}, 1 \mathrm{~h}$} \\
\hline & $\begin{array}{l}\text { Starting } \\
\text { amine }\end{array}$ & $\begin{array}{l}\text { Monoacetylated } \\
\text { product }\end{array}$ & $\begin{array}{l}\text { Starting } \\
\text { amine }\end{array}$ & $\begin{array}{l}\text { Monoacetylated } \\
\text { product }\end{array}$ \\
\hline & 31 & 69 & 0 & 100 \\
\hline & 42 & 44 & 7 & 73 \\
\hline & 93 & 7 & 4 & $94^{\mathrm{a}}$ \\
\hline
\end{tabular}

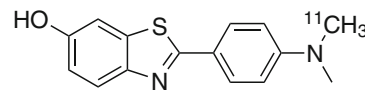

10

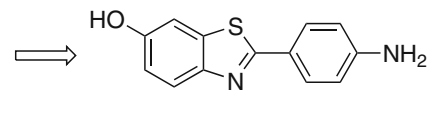

11
Scheme 3 Chemical structures of $\left[{ }^{11} \mathrm{C}\right] \mathrm{PIB} \mathbf{1 0}$ used for the in vivo imaging of Alzheimer's disease and the precursor $\mathbf{1 1}$ used for the radiosynthesis

aged 65 and older suffers from dementia, which represented 36 millions people worldwide in 2010 with a total societal cost estimated to be US\$ 604 billions. It is associated with the gradual accumulation of two proteins in the brain, the $\beta$-amyloid protein and the protein tau [11].

The Pittsburgh compound B ([ $\left.\left.{ }^{11} \mathrm{C}\right] \mathrm{PIB}\right) \mathbf{1 0}$ is an analogue of thioflavin-T (dye used for the histological marker of $\beta$-amyloids plaques), that belongs to the family of neutral compounds containing a benzothiazole ring. This compound shows a high affinity for amyloid aggregates and is a promising candidate for PET imaging. Nowadays, the $\left[{ }^{11} \mathrm{C}\right] \mathrm{PIB}$ in clinical phase III trial, is the radiotracer the gold-standard amyloid PET tracer used in research to reveal amyloid aggregates in vivo PET and represents the reference compound for the evaluation of new markers of $\beta$-amyloids aggregates (Scheme 3) [12].

Although $\left[{ }^{11} \mathrm{C}\right] \mathrm{PIB}$ showed an excellent pharmacokinetic profile for PET imaging, its clinical use is limited to hospitals with a cyclotron capable of generating the isotope carbon-11, with a half-life very short (20.4 min). The development of fluorine-18 labeled compounds, whose half-life duration is greater (109.8 $\mathrm{min})$ is necessary to obtain a diagnostic tool marketable. Some fluorinated derivatives with benzothiazoles or imidazopyridine ring have been described [13].

The commonly used method for the synthesis of the precursor 11 of $\left[{ }^{11} \mathrm{C}\right] \mathrm{PIB}$ requires the protection of the phenolic function or the use of a nitro group as precursor of the amine function. It involves a five-step synthesis with quite low overall yields ranging from 24 to $39 \%$. Few improved syntheses are reported in the literature using a Suzuki-Miyaura coupling or Heck coupling reaction with 35 and $66 \%$ yields, respectively. In both cases the protection of the phenol function is necessary [14-16].

Encouraged by the high interest in the $\left[{ }^{11} \mathrm{C}\right] \mathrm{PIB}$ for Alzheimer's disease diagnostic research and considering these previous studies, we decided to develop a direct synthesis of the precursor 2 of $\left[{ }^{11} \mathrm{C}\right] \mathrm{PIB}$ from two commercially available reagents, by a Suzuki-Miyaura coupling reaction. After optimization of reaction conditions between the 2-bromo-6-hydroxybenzothiazole $\mathbf{1 2}$ and the pinacol ester of 4-aminophenylboronic acid 13 the desired compound 14 was isolated by precipitation in $94 \%$ yield (Scheme 4) [17].

These Suzuki-Miyaura conditions were successfully extended to the synthesis of several functionalized 2-arylbenzothiazoles $\mathbf{1 7}$ in high yields (70-98\%) (Scheme 5). The hydroxy and amino substituents were compatible with the described conditions without additional functional protection. The synthesis of compounds containing nitro substituents was also very efficient using the conditions reported.

We studied and compared the coupling reaction of Suzuki-Miyaura in thermal conditions and under microwave activation. The microwave conditions for the synthesis of each series of arylbenzothiazoles were optimized. A preliminary study was developed using different conditions of temperature and activation power. The catalytic system ( $5 \mathrm{~mol} \%$ of $\mathrm{Pd}(\mathrm{dppf}) \mathrm{Cl}_{2} \mathrm{CH}_{2} \mathrm{Cl}_{2}$ ) used for reactions under conventional heating was compatible with microwave conditions and rapid couplings were observed within $5 \mathrm{~min}$ at $60{ }^{\circ} \mathrm{C}$ and total conversion was obtained after $15 \mathrm{~min}$ instead of $1.5-6 \mathrm{~h}$ with conventional heating. The results and the reaction conditions used are described in Table 2 [17]. 
Scheme 4 Suzuki-Miyaura coupling reaction leading to the precursor 14 of the radiochemical tracer $\left[{ }^{11} \mathrm{C}\right] \mathrm{PIB}$ 10

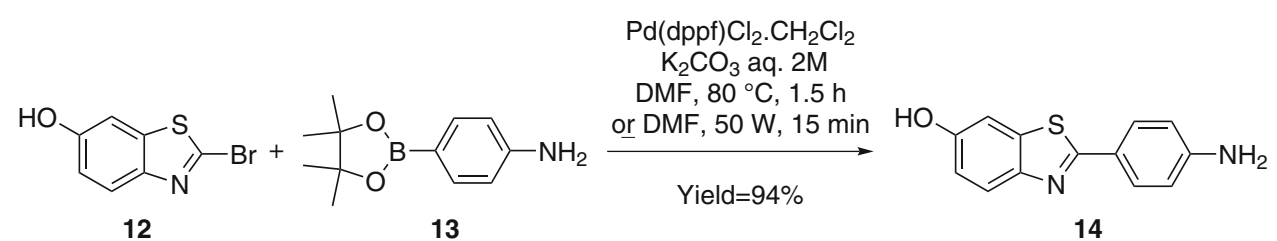

13
Scheme 5 Biaryl coupling of 2-bromobenzothiazoles 15 with various phenyl and pyridinylboronic acid pinacol esters

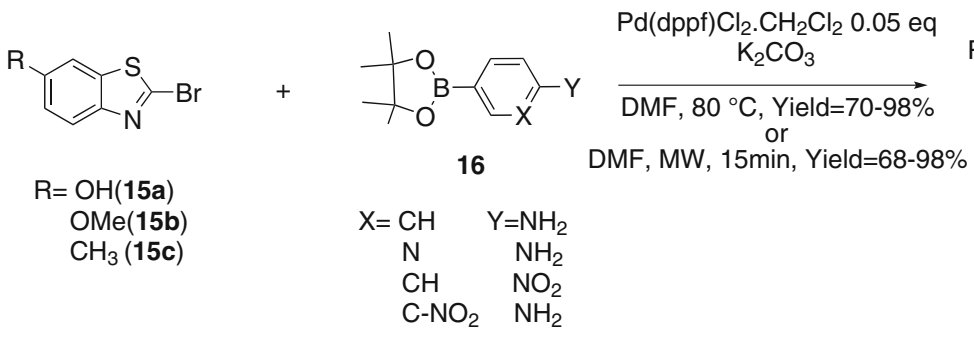

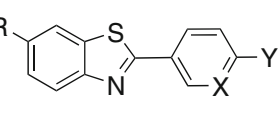

17
Table 2 Biaryl coupling of 2-bromobenzothiazoles 15 with various phenylboronic acid pinacol esters performed by microwave activation

\begin{tabular}{|c|c|c|c|c|c|}
\hline \multirow[t]{2}{*}{ Aryl halide (15) } & \multirow[t]{2}{*}{ Boronic acid pinacol ester (16) } & \multicolumn{2}{|c|}{ Heating conditions } & \multicolumn{2}{|c|}{$\begin{array}{l}\text { Microwave } \\
\text { conditions } 15 \mathrm{~min}\end{array}$} \\
\hline & & Time $(\mathrm{h})$ & Yield $^{\mathrm{a}}(\%)$ & Power, $\Delta$ & Yield $^{\mathrm{a}}(\%)$ \\
\hline 15a $(\mathrm{OH})$ & & 1.5 & 94 & $10 \mathrm{~W}, 60^{\circ} \mathrm{C}$ & 93 \\
\hline $15 \mathbf{a}$ & & 1.5 & 95 & $10 \mathrm{~W}, 60^{\circ} \mathrm{C}$ & 92 \\
\hline 15a & & 1.5 & 70 & $10 \mathrm{~W}, 60^{\circ} \mathrm{C}$ & 87 \\
\hline $15 \mathbf{a}$ & & 1.5 & 98 & $10 \mathrm{~W}, 60^{\circ} \mathrm{C}$ & 85 \\
\hline 15b (OMe) & & 3 & 97 & $50 \mathrm{~W}, 60^{\circ} \mathrm{C}$ & 98 \\
\hline 15b & & 6 & 98 & $50 \mathrm{~W}, 150{ }^{\circ} \mathrm{C}$ & 68 \\
\hline $15 b$ & & 1.5 & 78 & $50 \mathrm{~W}, 60^{\circ} \mathrm{C}$ & 96 \\
\hline $15 \mathrm{c}(\mathrm{Me})$ & & 1.5 & 99 & $50 \mathrm{~W}, 80^{\circ} \mathrm{C}$ & 84 \\
\hline
\end{tabular}

${ }^{\text {a }}$ Yields refer to isolated products 17

The high yields (68-98\%) and short reaction times provided by the microwave-assisted Suzuki-Miyaura cross-coupling described here are decisive advantages. As expected, the unprotected phenol and amine functions are well tolerated by these coupling conditions, which makes this synthesis a very straightforward route to get the precursor of the $\left[{ }^{11} \mathrm{C}\right] \mathrm{PIB}$ and other derivatives.
Ultrasonically activated reduction of substituted nitrobenzenes

As part of an ongoing program concerning a photoinduced single electron transfer reaction to synthesize anisomycin, an antitumor substance, we were interested in the chemoselective preparation of hydroxylamines. The 


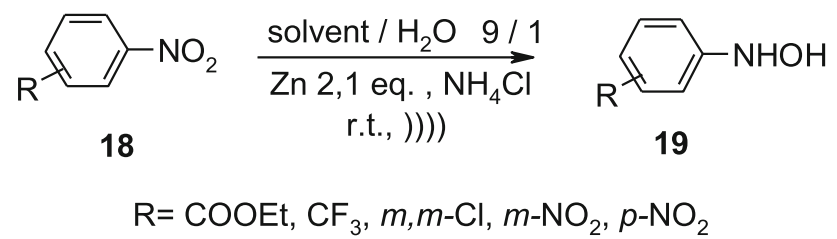

Scheme 6 Preparation of arylhydroxylamines 19 by reduction of nitroaromatic compounds $\mathbf{1 8}$ assisted by ultrasound

arylhydroxylamines are an important class of compounds frequently used as building blocks in the synthesis of numerous fine chemicals. We thus decided to study this transformation. Several methods have been developed for the preparation of arylhydroxylamines $\mathbf{1 9}$. The more conventional one involves the reduction of nitroaromatic compounds 18 to the corresponding $N$-hydroxylamines 19. The procedure typically used employs a catalytic amount of a heavy metal (palladium, rhodium, iridium, or Raney nickel) together with hazardous reagents (metallic selenium or tellurium with sodium borohydride or bismuth chloride with potassium borohydride).

In order to improve this reduction procedure in terms of selectivity and efficiency (yield and reaction time), we were interested in studying the effect of ultrasounds on the reaction. The advantageous use of ultrasound irradiation technique for activating various reactions proceeding, via electron transfer mechanism or radical route, is well documented in the literature, particularly for solidliquid heterogeneous reactions which undergo pulverization of solid particles and simultaneous activation of surface [6].

We decided to study this reduction procedure in terms of selectivity by exploiting the advantages of ultrasound as activation mode and using zinc as catalyst (Scheme 6).

The first protocols using ethyl 4-nitrobenzoic acid ester allowed us to optimize the experimental conditions. Thus, 2.1 eq. of zinc in a mixture of ethanol: water (9:1) in the presence of ammonium chloride under ultrasonic irradiation affords in 3-5 min the expected hydroxylamines 19 with yield of approximately $90 \%$ [18].

The use of acetone instead of ethanol increased yields (95-100 \%) for all substrates. In the case of aromatic groups substituted by electron withdrawing groups the reactions were quantitative and the hydroxylamines obtained were stable. No by-product "over-reducted" was observed. In this study we have demonstrated that depending on the quantity of zinc dust, the nature of the medium and the time of ultrasonication, it is possible to control the access to other products of "over-reduction" [18].
Synthesis of $\beta^{3}$-amino acids from novel $N$-protected $\beta^{3}$ amino nitriles by a bioconversion step using nitrilases

The $\beta$-amino acids $\mathbf{2 0}, \mathbf{2 1}, \mathbf{2 2}$ are not very common in nature and they are often metabolites of natural compounds (Fig. 1). They are key intermediates present in various structures of bioactive molecules. The $\beta$-amino acids are becoming increasingly used in the field of peptidomimetics for the development of $\beta$-peptides [19]. Consequently, the development of new synthetic routes to access to enantiomerically pure $\beta$-amino acids has become an important research area. One of the simple pathways to prepare $\beta$ amino acids is the homologation of the corresponding $\alpha$ amino acids.

We were interested in developing a new synthesis pathway of $\beta 3$-chiral amino acids 28 simple, stereoselective and feasible on a large scale. The synthetic strategy developed is based on the synthesis of $\beta 3$-amino nitriles $\mathbf{2 7}$ via the preparation and regioselective opening of chiral aziridines $\mathbf{2 5}$ or via the nucleophilic substitution by the nitrile group of $N$-protected $\beta$-aminoalcohols 26 (Scheme 7) [20].

We considered access to the $\beta^{3}$-amino acids 28 from activated aziridines 25 preparing in a first time the $N$ protected $\beta$-aminonitriles 27. The final step of the synthesis involved a nitrilase-catalyzed hydrolysis of nitriles. The first attempts of biotransformation using expressed nitrilases from several bacterial strains were unsatisfying. These results encouraged us to use purified nitrilases commercially available simplifying considerably the experimental protocol. Twelve nitrilases (NIT-101-NIT-112) "ready for use" were studied. The best rates of biotransformation were obtained using NIT-107 with a substrate concentration of $0.05 \mathrm{M}$. The influence of the nature of the protecting groups on the biotransformation was evaluated; $100 \%$ of conversion was obtained with the aliphatic $\beta^{3}$-aminonitriles derived from L-alanine [20]. These experiments showed the high efficiency of the enzymes, in terms of yield and selectivity. Such reactions do not require solvent or heating.
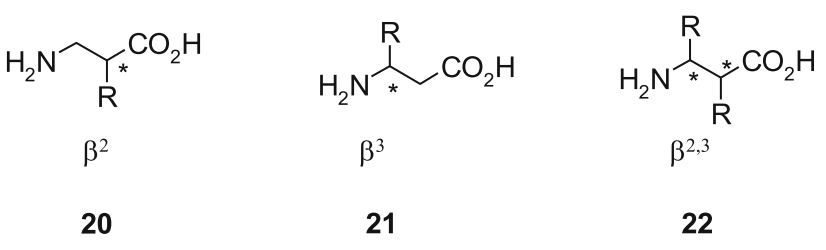

Fig. 1 Structure of $\beta$-amino acids 


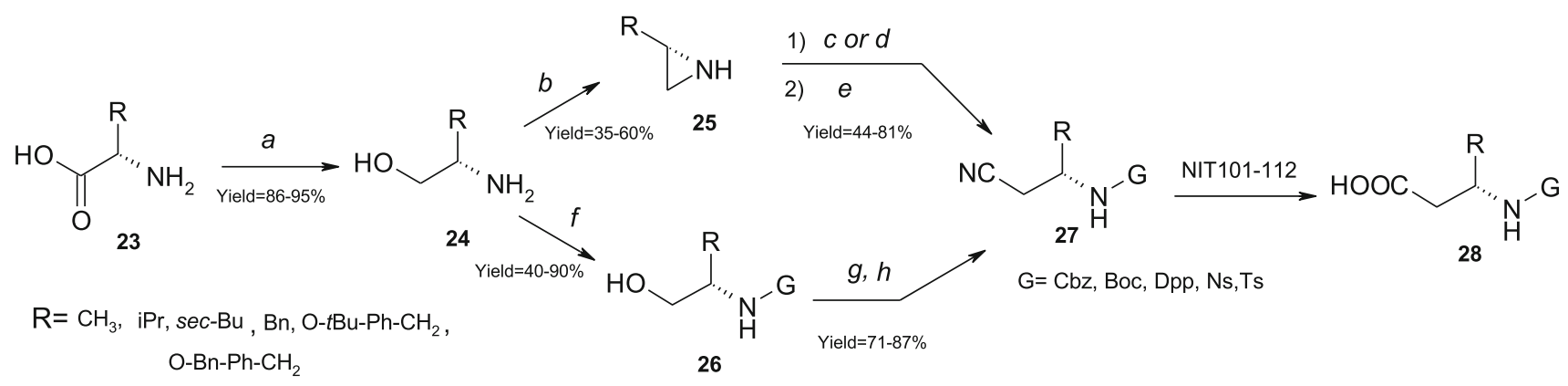

Scheme 7 Synthesis of $N$-protected $\beta^{3}$-amino acids 28. (a) $\mathrm{NaBH}_{4}$, $\mathrm{ZnCl}_{2}$, THF; (b) $\mathrm{PPh}_{3} / \mathrm{DEAD}$, THF ou toluene (c) $\mathrm{CbzCl}, \mathrm{CH}_{3} \mathrm{CN}$; (d) $\mathrm{DppCl}$, TEA, THF, $0{ }^{\circ} \mathrm{C}$; (e) $\mathrm{NaCN}, \mathrm{CH}_{3} \mathrm{CN} / \mathrm{H}_{2} \mathrm{O}$ 9:1, reflux; (f) $\mathrm{CbzCl}$, TEA $\mathrm{CH}_{2} \mathrm{Cl}_{2}$ (or THF) ou $\mathrm{Boc}_{2} \mathrm{O}, \mathrm{NaOH}$, dioxane ou $\mathrm{TsCl}$ (ou ${ }_{4} \mathrm{NsCl}$ ), $\mathrm{NaHCO}_{3}$, THF (g) MsCl, TEA, THF; (h) NaCN, DMF
Scheme 8 General procedure for the $\alpha$-alkylation of aldehydes 29 by photoredox organocatalysis

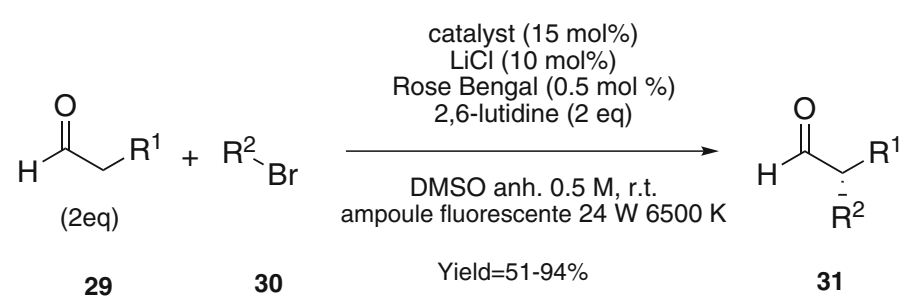

$\alpha$-alkylation of aldehydes by photoredox organocatalysis

We have developed a catalytic process, without transition metal, using visible light and dyes as catalysts having the same redox properties as that of the metal complexes. Photoredox catalysis with Rose Bengal provided very interesting results at room temperature under mild reaction conditions and with short irradiation times (scheme 8) [21].

The $\alpha$-alkylation of aldehydes $\mathbf{2 9}$ was completed after $2 \mathrm{~h}$ irradiation at room temperature with excellent yields using a high-pressure mercury vapor lamp of $150 \mathrm{~W}$, or an eco-friendly fluorescent lamp of $24 \mathrm{~W}$ at $6500 \mathrm{~K}$, or under irradiation, LED, with good yields. Finally reaction was also carried out under sunlight irradiation with $87 \%$ yield [21].

\section{Conclusions}

Nowadays, green chemistry plays an important role in the development of innovative strategies from raw materials and renewable energy while producing minimal waste. In this study we described several green physicochemical activation methods, used in our research group, to prepare high added value molecules. These different physicochemical activation techniques such as microwaves, ultrasound, biotransformation and photocatalysis are better for the environment by using less energy, emit less solvent and allow to increase efficiency in the preparation of new compounds. They are inestimable tools to complement the traditional methods used in organic synthesis.

Acknowledgments The National Centre for Scientific Research (CNRS), the MENRT and Guerbet Group are acknowledged by their financial support. The authors thank Professor Georges Descombes for invitation to present our researches at the COFRET'14 and for his advice during the process of revision.

Authors' contributions The authors contributed equally to this work. They read and approved the final manuscript.

Conflict of interest The authors declare that they have no conflict of interest.

Open Access This article is distributed under the terms of the Creative Commons Attribution License which permits any use, distribution, and reproduction in any medium, provided the original author(s) and the source are credited.

\section{References}

1. Campagne, J.M., Agbossou, F., Ayad, T., Baudoin, O., Buono, G., Chataigner, I., Crévisy, C., Dez, I., Donnard, M., Fache, F., Feasson, C., Gaumont, A.C., Giordano, L., Hesemann, P., Marsais, F., Mauduit, M., Michelet, V., Mortreux, A., Phansavath, P., Piva, O., Roblin, J.P., Rouden, J., Taillefer, M., Toullec, P., Tschamber, T., Vidal, V.: Towards a green molecular chemistry. Actualité chimique 338-339, 14-27 (2010)

2. Charpentier, J.C.: Perspective on multiscale methodology for product design and engineering. Comput. Chem. Eng. 33, 936-946 (2009) 
3. Hafez, E.A.A., Al-Mousawi, S.M., Moustafa, S.M., Sadek, K.U., Elnagdi, M.H.: Green methodologies in organic synthesis: recent developments in our laboratories. Green Chem. Lett. Rev. 6, 189-210 (2013)

4. Kappe, CO, Stadler, A: Microwaves in Organic and Medicinal Chemistry, vol 25, Wiley Ed (2005)

5. Dallinger, D., Lehmann, H., Moseley, J.D., Stadler, A., Kappe, C.O.: Scale-up of microwave-assisted in a multimode bench-top reactor. Org. Process Res. Dev. 15, 841-854 (2011)

6. Luche, JL: Synthetic Organic Sonochemistry: Kluwer Academic/ Plenum: Hingham, (1998)

7. Faber, K: Biotransformations in Organic Chemistry, 5ème Ed Springer (2003)

8. Pham, P.V., Nagib, D.A., MacMillan, D.W.C.: Photoredox Catalysis: A Mild, Operationally Simple Approach to the Synthesis of $\alpha$-Trifluoromethyl Carbonyl Compounds. Angew. Chem. Int. Ed. 50, 6119-6122 (2011)

9. Ferroud, C., Borderies, H., Lasri, E., Guy, A., Port, M.: Synthesis of a novel amphiphilic GdPCTA-[12] derivative as a potential micellar MRI contrast agent. Tetrahedron Lett. 49, 5972-5975 (2008)

10. Ferroud, C., Godart, M., Ung, S., Borderies, H., Guy, A.: Microwaves -assisted solvent-free synthesis of $N$-acetamides by amidation or aminolysis. Tetrahedron Lett. 49, 3004-3008 (2008)

11. Batsch, N.L., Mittelman, M.S.: Overcoming the stigma of dementia. Alzheimer's Disease International, World Alzheimer Report (2012)

12. Svedberg, M.M., Rahman, O., Hall, H.: Preclinical studies of potential amyloid binding PET/SPECT ligands in Alzheimer's disease. Nucl. Med. Biol. 39, 484-501 (2012)

13. Klunk, W.E., Lopresti, B.J., Ikonomovic, M.D., Lefterov, I.M., Koldamova, R.P., Abrahamson, E.E., Debnath, M.L., Holt, D.P., Huang, G.F., Shao, L., DeKosky, S.T., Price, J.C., Mathis, C.A.:
Binding of the positron emission tomography tracer Pittsburgh compound-B reflects the amount of amyloid- $\beta$ in Alzheimer's disease brain but not in transgenic mouse brain. J. Neurosci. 25, 10598-10606 (2005)

14. Mathis, C.A., Wang, Y., Holt, D.P., Huang, G.F., Debnath, M.L., Klunk, W.E.: Synthesis and evaluation of 11C-labeled 6-substituted 2-arylbenzothiazoles as amyloid imaging agents. J. Med. Chem. 46, 2740-2754 (2003)

15. Shi, D.F., Bradshaw, T.D., Wrigley, S., McCall, C.J., Lelieveld, P., Fichtner, I., Stevens, M.F.: Antitumor benzothiazoles. 3. Synthesis of 2-(4-aminophenyl)benzothiazoles and evaluation of their activities against breast cancer cell lines in vitro and in vivo. J. Med. Chem. 39, 3375-3384 (1996)

16. Bonin, H., Leuma-Yona, R., Marchiori, B., Demonchaux, P., Gras, E.: Highly practical boronic acid surrogates for the SuzukiMiyaura cross-coupling. Tetrahedron Lett. 52, 1132-1135 (2011)

17. Bort, G.: Sylla-Iyarreta Veitia, M, Ferroud, C: Straightforward synthesis of PET tracer precursors used for the early diagnosis of Alzheimer's disease through Suzuki-Miyaura cross-coupling reactions. Tetrahedron 69, 7345-7353 (2013)

18. Ung, S., Falguières, A., Guy, A., Ferroud, C.: Ultrasonically activated reduction of substituted nitrobenzenes to corresponding $\mathrm{N}$-arylhydroxylamines. Tetrahedron Lett. 46, 5913-5917 (2005)

19. Juaristi, E, Soloshonok V: Enantioselective Synthesis of $\beta$-amino acids, 2ème Ed Wiley Interscience (2005)

20. Veitia, Sylla-Iyarreta: M, Brun, PL, Jorda, P, Falguières, A, Ferroud, C: Synthesis of $N$-protected $B 3$-amino nitriles: study of their hydrolysis involving a nitrilase-catalysed step. Tetrahedron Asymmetry 20, 2077-2089 (2009)

21. Fidaly, K., Ceballos, C., Falguières, A.: Sylla-Iyarreta Veitia, M, Guy, A, Ferroud, C: Visible light photoredox organocatalysis: a fully transition metal-free direct asymmetric $\alpha$-alkylation of aldehydes. Green Chem. 14, 1293-1297 (2012) 